\title{
ORGANIZATION OF THE PUBLIC PROCUREMENT PROCESS AT THE LEVEL OF THE CONTRACTING AUTHORITIES IN ROMANIA. PARTICULARITIES AND SOLUTIONS FOR THE MANAGEMENT OF PUBLIC PROCUREMENT PROCEDURES ORGANIZED IN THE CONTEXT OF EMERGENCY OF COVID-19 CRISIS
}

\author{
Ceocea Costel \\ "Vasile Alecsandri" University of Bacău \\ cceocea@sifm.ro \\ Ceocea Raluca Alexandra \\ "Gh. Asachi” University of Iaşi \\ raluca.ceocea@gmail.com \\ Vatamaniuc Adrian \\ "Gh. Asachi”" University of Iași \\ adrian.vatamaniuc@gmail.com \\ Mihălaș Vasile \\ "Vasile Alecsandri”" University of Bacău \\ mihalas2018@gmail.com
}

\begin{abstract}
The normative framework applicable to public institutions imposes an approach to public procurement management aimed at awarding public procurement contracts in conditions of economic and social efficiency. Achieving the objectives set at the level of the organization, in accordance with the principles underlying the award of public procurement contracts is conditioned by the adoption and implementation of specific procedures, mainly oriented towards the organization of decision-making processes. In the context of the crisis triggered by the new Coronavirus SARS-CoV-2, contracting authorities were forced to organize public procurement processes, in a matter of urgency, on a procedural background less oriented towards adopting fast and efficient decisions, with negative effects both on the available financial resources and on the process of ensuring the flow of products, services and works corresponding to the rhythm imposed by the urgent needs of public institutions involved in managing the effects of the health crisis. This paper aims at individualize the decision-making process in the field of public procurement in Romania, in order to identify models of good practice, procedures and support working tools for optimizing the public procurement process carried out at the level of contracting authorities in a matter of emergency.
\end{abstract}

\section{Keywords}

Romania; procedures; public procurement management; change management; decision-making; urgency; crisis; economic and social efficiency; SARS-CoV-2

\section{JEL Classification}

D73; H12; H57

\section{Introduction}

The concept of management, as a general approach, refers to a strategic process of organizing activities in order to achieve certain objectives assumed at the level of the organization. 
Regarding the private organizations, management objectives are mainly aimed at maximizing profit or achieving other personal goals (e.g. the need to achieve of the leaders, securing a portfolio of clients, increasing knowledge, etc.).

In contrast to the management of private organizations, public management mainly aims at achieving a general interest.

In the literature, confusions are often identified between the concept of public management and the concept of public administration.

Thus, the public administration is the expression of the activities undertaken for the fulfillment of the state functions and of the administrative-territorial structures, according to a framework regulated by normative acts.

In other words, public administration activities represent activities performed by responsible persons/civil servants, who have drawn competencies to act in order to perform public services, by issuing and/or implementing public laws.

Even if by the way it manifests itself, mainly due to the political character that determines them, between public administration and public management elements of interdependence are identified, between the two concepts the sign of equality cannot be put. In contrast to the concept of public administration which is strictly legal by the applicable legal framework, the concept of public management has evolved with the development of the functions of public sector organizations, with the development of theories on organization management and the evolution of the organizational and principled framework in which public organizations carries out their activities.

Thus, public management brings together a set of processes and managerial relationships that occur at the level of the components of the administrative system, which aim to create the appropriate institutional framework to enable the general public interest to be satisfied.

Even in this framework defined above, the literature tends towards an approximation of these two concepts, a fact also identified at the level of the Romanian university environment. Thus, public administration tends to be properly defined as "the use of managerial, political and legal theories and processes in order to fulfill the mandates of the legislative, executive and judicial government, in order to ensure the regulations and services for the society as a whole, as well as for its segments" (Alexandru, 2003, p.10).

Moreover, it is found that the link between administration and management is the "decision-making process" process specific to management which, "is the heart of administration, and the vocabulary of administrative theory must derive from the logic and psychology of human choice”. (Simon, 1979)

\section{Public procurement management}

\subsection{The concept of management at the level of public institutions}

As in the case of private organizations, the processes carried out at the level of public institutions can be divided into two categories: execution processes and management processes.

In detail, the execution processes within the public institutions are usually reduced to bureaucratic processes that have as main result the obtaining of some services or deliverables, which contribute to the achievement of the objectives established at the level of the institution. In contrast to the execution processes, the management processes within the public institutions are manifested by decisional acts.

The new Public Management, one of the strongest international currents in this domain, brings new ways to develop the sphere of public management. 
Even if the current of the New Public Management brings mainly a new attitude regarding the way the public administrative act is carried out, its orientation towards increasing the cost / efficiency ratio in the public sector requires both the import and the adaptation of specific management methods and techniques from private sector toward public organizations as well as the restructuring and optimization of the decision-making process within them.

Decentralization of public administration, implementation of public policies through projects, increasing the training of officials and clerks, improved organization of public institutions, digitalization of the public administration sector, new attitudes towards the citizen-client impose new guidelines of public administrations, the new role of public management being to ensure the transition from an empirical leadership style to a scientifically based one, based on knowledge and innovation.

The managerial decision within public institutions is a manifestation of the will of the administrative bodies, prior to the actions proposed to be undertaken, through which a solution is chosen, in order to achieve the proposed goal or objective or to achieve a desired result. This decision is usually taken when several appropriate possibilities or options are identified, which comply with the applicable legal framework, the selected option being the one that is identified as the most advantageous in relation to the institutional objectives assumed.

A definition, with a systemic profile, is given by Armenia Adroniceanu, presenting the administrative decision as "a complex process of choosing a decision-making variant from several possible ones, in order to achieve a public administration objective and influencing the activity of at least, another person in the system, the system as a whole or society in general" (Adroniceanu, 1999).

\subsection{The decision-making process}

Analyzing carefully the decision-making process carried out at the level of public institutions, we find that it involves:

$\checkmark$ collaboration of several people from the organizational structures of the institution

$\checkmark$ processing a large volume of information

$\checkmark$ carrying out the process in several stages

$\checkmark$ endorsement by one or more competent persons

$\checkmark$ assuming the responsibility of one or more persons holding public positions (Dulschi, 2016).

In the decision-making process, as a process of analysis and evaluation of several alternatives, the following main elements are identified:

$>$ The decision maker - represented by the person or group of persons who are to adopt the optimal variant from those possibly identified.

$>$ The problem subject to the decision - represented by the object of the decision

$>$ Decision variants - represented by the identified options

$>$ Decision-making criteria - represented by the characteristics on the basis of which the decision-making variants are evaluated and compared for the purpose of ranking and selecting the optimal variant

$>$ Decision-making environment - represented by the context given by the internal and external conditions that influence the decision

$>$ The set of consequences - represented by the results estimated to be obtained by adopting the decisional variants, established in relation to each decisional criterion separately

$>$ Decision objectives - the results intended to be achieved by the decision maker following the implementation of the selected decision variant. 
The decision-making process that should underlie the decision-making of the public decision-maker should move away from the administrative model (limited rational model) or the retrospective model (specific to public authorities with low managerial capacity) and move towards a rational model (classic) built on the following steps:

I. Establishing the institutional objectives pursued

II. Collection, verification, processing and analysis of information

III. Elaboration of options and quantification of the expected results of each option

IV. Selecting the most advantageous option

V. Putting into practice the selected variant, controlling the execution process and evaluating the results obtained.

\subsection{Public procurement management}

Although an insufficient allocation of financial resources is constantly invoked to the portfolio of needs generated by public institutions in Romania, it was found an inadequate management of public procurement processes, characterized by wrong/poor procurement, which generated waste of public funds and consumption of goods, services and unjustified works in relation to the institutional objectives established by the multitude of strategies assumed at their level.

In addition, European officials are constantly calling for the need to increase administrative capacity at the level of public institutions in order to increase the absorption of EU funds, based on unfavorable reports on frequent deviations of the public procurement from the legislative framework and related sanctions.

We appreciate that the optimal solution to improve the public procurement process carried out at the level of public institutions in Romania is one that aims to take over from the private sector some management techniques and methods, by adapting them to the specific constrains of the public administration sector.

As indicated in Public Procurement Law ${ }^{1}$, the managerial decisions that will be adopted regarding the public procurement processes must take into account the principles underlying the award of public procurement contracts, according to figure no. 1 below:

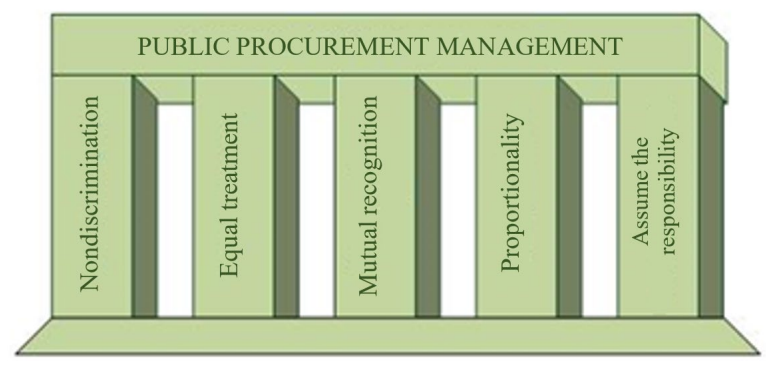

Figure 1 Principles underlying public procurement management

Source: authors, based on the Public Procurement Law no 98/2016

Given that the procurement process is a multidisciplinary one, involving all organizational structures on a variable basis, the managerial decisions that can be taken regarding public procurement must comply with the formalization and approval /approval process required by the regulatory framework applicable to all processes carried out at the level of the public institution and must aim mainly at achieving institutional objectives.

\footnotetext{
${ }^{1}$ Article 2 (2) form Public Procurement Law no 98/2016
} 
The main objectives that can be set at the level of a public institution with regard to the procurement process carried out at its level are:

$\checkmark$ ensuring the institution with a flow of products, services and works corresponding to the level and pace required by the objective needs established at the institution level

$\checkmark$ obtaining the products, services and works required in the context of economic and social efficiency

$\checkmark \quad$ conduct of contractual relations concluded by procurement processes under optimal conditions, respecting the principle of legality and contractual balance

The stages at which the procurement process is carried out, in accordance with the regulatory frame ${ }^{2}$ are:

A. Planning/preparation phase, including market consultation

B. Stage of organization of the procedure and award of the contract/framework agreement

C. Post-award stage of the contract/framework agreement execution and monitoring of the implementation of the contract/framework agreement

In order to advance the above stages, the specific tools for planning and monitoring public procurement processes that may be available to contracting authorities are:

a) Public Procurement Strategy

b) Annual Public Procurement Program

c) GANTT chart

d) Risk Management Plan / Risk Register

e) Contracting strategy

The characteristics of contracting authorities according to which the structuring of decision-making processes must be adjusted are:

$>$ Type of contracting authority and its main activity

$>$ Volume and complexity of the public procurement portfolio

$>$ Number of people involved in procurement processes

$>$ Training policy for staff involved in procurement processes.

Considering the results of the research activity carried out so far, according to the above conclusions, we outlined the following conceptual model that underlies the analysis of the decision-making process in the field of public procurement.

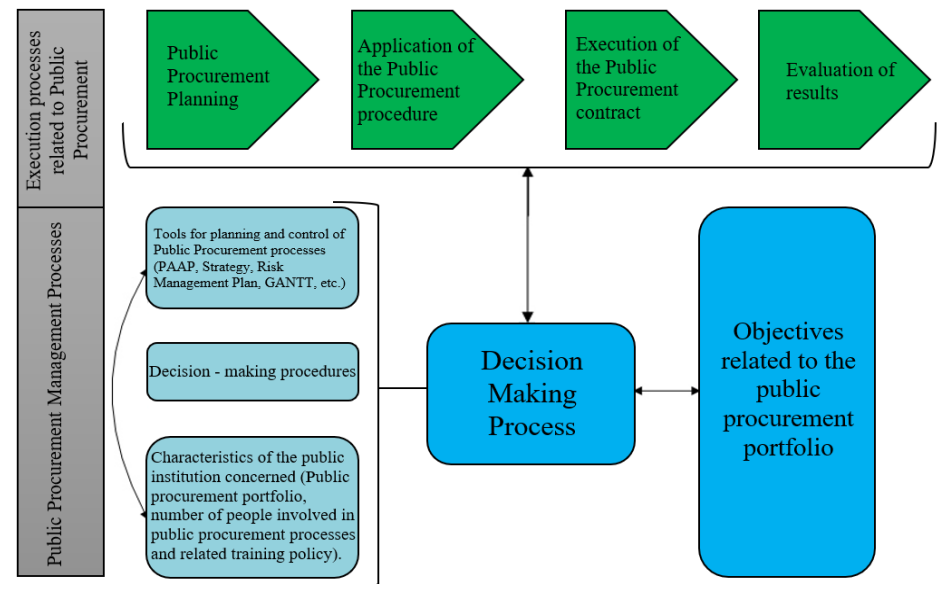

Figure 2 Conceptual model on the decision-making process in public procurement

Source: Authors

\footnotetext{
${ }^{2}$ Article 8.(2) of the Methodological Norms for the application of the public procurement law, published by Government Decision no. 395/2016
} 


\title{
3. Public procurement-specific decision-making process in the context of the emergency situation triggered by the COVID-19 outbreak
}

\author{
3.1. Analysis of the context in which public procurement was carried out \\ during the emergency period
}

The field of public health has caught the full attention of experts and policy makers throughout the first 5 months of 2020. What at first seemed just another flu epidemic, has turned into an event of cataclysmic proportions, both in terms of the number of diseases, as well as the pressure on economic systems and especially public health systems. Against this background, the political response mechanisms, decision-making systems and support infrastructure proved to be more or less effective, the moment we present our conclusions in view of being within the limits of an evaluation in medias res, the epidemic not being fully stopped.

Obviously, this pandemic landscape has changed the paradigm in which decisions have been taken in the public sector, especially within institutions that have played an active role in the action plans applied for combating the spread of COVID-19 Coronavirus and manage the consequences.

Thus, as a result of the onset of the state of emergency, by issuing Decree no. 195 / 16.03.2020, published in the Official Journal of Romania no. 212 of 16.03.2020, the contracting authorities involved in actions to combat and manage the consequences of the pandemic, from the point of view of public procurement, were transposed into a new framework that required the procurement in a short time of significantly more large amounts of products needed to combat and manage the effects of the epidemic.

This new picture of public procurement triggered by the health crisis COVID19 was characterized by an inaccurate legislative framework, insufficient administrative capacity and a market dominated by a growing demand.

In the process of establishing the state of emergency by Decree no. $195 / 16.03 .2020$, "probably" due to the pressure of the moment, certain terms were used, inappropriately, a phenomenon likely to generate confusion among the contracting authorities.

For example in the text of Decree no. 195 / 16.03.2020 identifies the inappropriate use of public procurement-specific terminology such as "procurement in direct mode" 3 (and not through "direct procurement") or "direct procurement procedure" 4 (taking into account that direct procurement t $^{5}$ is not defined as a competitive public procurement procedure). Anticipating possible dichotomies, misunderstandings, induced interpretations, National Agency for Public Procurement through a notification published on the institution's website on 16.03.2020, reiterated the incidence of the legislative framework established by Public Procurement Law no 98/2016 in the case of this state of emergency, which promotes the award of public procurement contracts through competitive procedures

We intuited that this state of confusion has variably characterized the entire EU space, which is why the European Commission issued Communication 2020 / C $108 \mathrm{I} / 01$ of 01.04.2020 on its guidelines for the use of the legal framework for public procurement in the case of the award of public procurement contracts in the event of emergency triggered by the COVID-19 crisis, which strengthens the incidence of using the competitive procedures established by Directive 2014/24 / EU (and assimilated at the

\footnotetext{
${ }^{3}$ Article 10 of Decree no. $195 / 16.03 .2020$

${ }^{4}$ Article 28 (2) of Romania no. 195 / 16.03.20200

${ }^{5}$ The direct procurement regulated by art. 43-46 of Government Decision no 395/2016, is not a public procurement procedure within the meaning of Art. 68 of Law 98/2016 but only a right offered to the contracting authority to purchase products, services or works with an estimated value below the limit imposed by art. 7 para. (5) of Law 98/2016, without using the competitive method of awarding these contracts.
} 
level of Public Procurement Law no 98/2016) in the case of awarding public procurement contract of products, services and works needed to deal with this crisis.

At the same time, the picture of public procurements in the emergency state was also affected by a low capacity of the teams involved in public procurement processes carried out in this period, both in terms of professional level and availability of their members.

Among the cases cited in the discussions between experts in various communication channels and specialized forums are:

$>$ reduced number of staff

$>$ low level of training, inadequate in relation to the particularities of the specific market of sanitary materials, protection materials, medical equipment, medications, etc.

$>$ the modification of the work schedule, the transfer of some employees under the telework contract regime, the lack of resources and infrastructure necessary to carry out the activities exclusively online

poor use or non-use of the facilities offered by the digital signature system.

Following the administration of a questionnaire at the level of several contracting authorities in the North-East region in $2019^{6}$, conclusions were drawn which, in retrospect, confirm the chronic existence of some of the problems mentioned above, namely:

$\checkmark$ Approx. 7\% of the contracting authorities involve in the procurement processes more than 6 persons, and approx. 35\% involve a number of 2-5 persons;

$\checkmark$ Over 78\% of contracting authorities do not use IT applications (other than Electronic Public Procurement System) for planning and managing public procurement processes;

$\checkmark$ Only $50 \%$ of the contracting authorities have implemented a continuous professional training program in the field of public procurement (with a participation frequency of max. 2 years);

$\checkmark$ Over $85 \%$ of the staff involved in public procurement processes have a total work experience of over 20 years, corroborated by the fact that over $64 \%$ of these staff are over the age of 45 (of which $28.6 \%$ over 55 for years).

And if these factors were not enough to increase the complexity of the decision-making process in the field of public procurement, the market to which emergency public procurement contracts were addressed also put additional pressure on the decisionmaking act, both by the unavailability in the market of the volumes of products requested by the contracting authorities and by the high volatility of the prices related to these products.

As elements that directly influenced the specific market of these materials and equipment we highlight:

$>$ Lack of domestic producers of such products, which would provide a predictability and guarantee of the availability of the requested products in agreed delivery schedules, producers to whom the public authorities could impose, according to $\mathrm{law}^{7}$, the amplification of the production process to cover the additional need generated by such a crisis;

$>$ Established restrictions on the international transport of goods, especially in trade relations between the European and Asian areas that have disrupted supply chains.

\footnotetext{
${ }^{6}$ Research report no. 3 advanced at the level of the Doctoral School within the University "Gh. Asachi” Iași (Vatamaniuc, 2019)

${ }^{7}$ Eg. Article 9 para. (1) of the Government Emergency Ordinance no. 1 of 21.01 .1999 on the state of siege and the state of emergency
} 
Lack of "buffer" stocks at importers and / or distributors with constant activity in this relevant market, ensuring a rapid supply immediately after the award of the public procurement contract;

$>$ The small-scale use in this market of the special method of awarding public contracts using "Framework Agreements", which provides for the option of purchasing additional quantities (compared to the current need) and which makes it possible to supply initial stocks of products quickly, without other bureaucratic formalities imposed by the applicable legal framework in the field of public procurement.

As an example of the above we can present the evolution of the unit price and the contracted volumes related to a product widely used in this health crisis, respectively "surgical mask", during the first four months of this year, according to the table below:

Table 1 Evolution of public procurement of surgical masks

(Jan.-Apr. 2020)

\begin{tabular}{|c|c|c|c|c|}
\cline { 2 - 5 } \multicolumn{1}{c|}{} & January & February & March & April \\
\hline $\begin{array}{c}\text { Number of } \\
\text { procurement } \\
\text { (according to } \\
\text { SEAP catalogue) }\end{array}$ & $\begin{array}{c}17 \\
\text { contracts }\end{array}$ & $\begin{array}{c}78 \\
\text { contracts }\end{array}$ & $\begin{array}{c}251 \\
\text { contracts }\end{array}$ & $\begin{array}{c}263 \\
\text { contracts }\end{array}$ \\
\hline $\begin{array}{c}\text { Quantity } \\
\text { purchased }\end{array}$ & $\begin{array}{c}60,990 \\
\mathrm{pcs}\end{array}$ & $\begin{array}{c}398,550 \\
\mathrm{pcs}\end{array}$ & $\begin{array}{c}1,376,280 \\
\mathrm{pcs}\end{array}$ & $\begin{array}{c}1,816,527 \\
\mathrm{pcs}\end{array}$ \\
\hline $\begin{array}{c}\text { Average unit price } \\
\text { (excluding VAT) }\end{array}$ & $0.17 \mathrm{lei} / \mathrm{pc}$ & $1.83 \mathrm{lei} / \mathrm{pc}$ & $3.75 \mathrm{lei} / \mathrm{pc}$ & $2.73 \mathrm{lei} / \mathrm{pc}$ \\
\hline
\end{tabular}

Source: Electronic Public Procurement System (SEAP)- extracted from direct purchases

http://e-licitatie.ro/pub

As a specific detail of a market dominated by the crisis, the table above shows a direct correlation between the dynamics of the unit purchase price $(+2,200.00 \%)$ and that of the volume of products purchased (+2,256.00\%).

As a result of this accumulation of factors that have contributed to the accentuation of the uncertainty and to the increase of the risk intensity, we consider as very probable the increase of the incidence of the decisional errors and/or of the deviations from the law.

The fact that most contracting authorities (Vatamaniuc, 2019) did not implement an internal procedure for decision-making in the field of public procurement $(71.4 \%)$ also contributed to this situation, even though the leaders of these contracting authorities equally recognize that the implementation of such a procedure would directly contribute to the achievement of the objectives set at the level of the institution (71.5\%). In summary, the way in which the public procurements were carried out during the emergency situation can be summarized and explained from the perspective of their specific causal relations, as presented in figure no. 3 . 


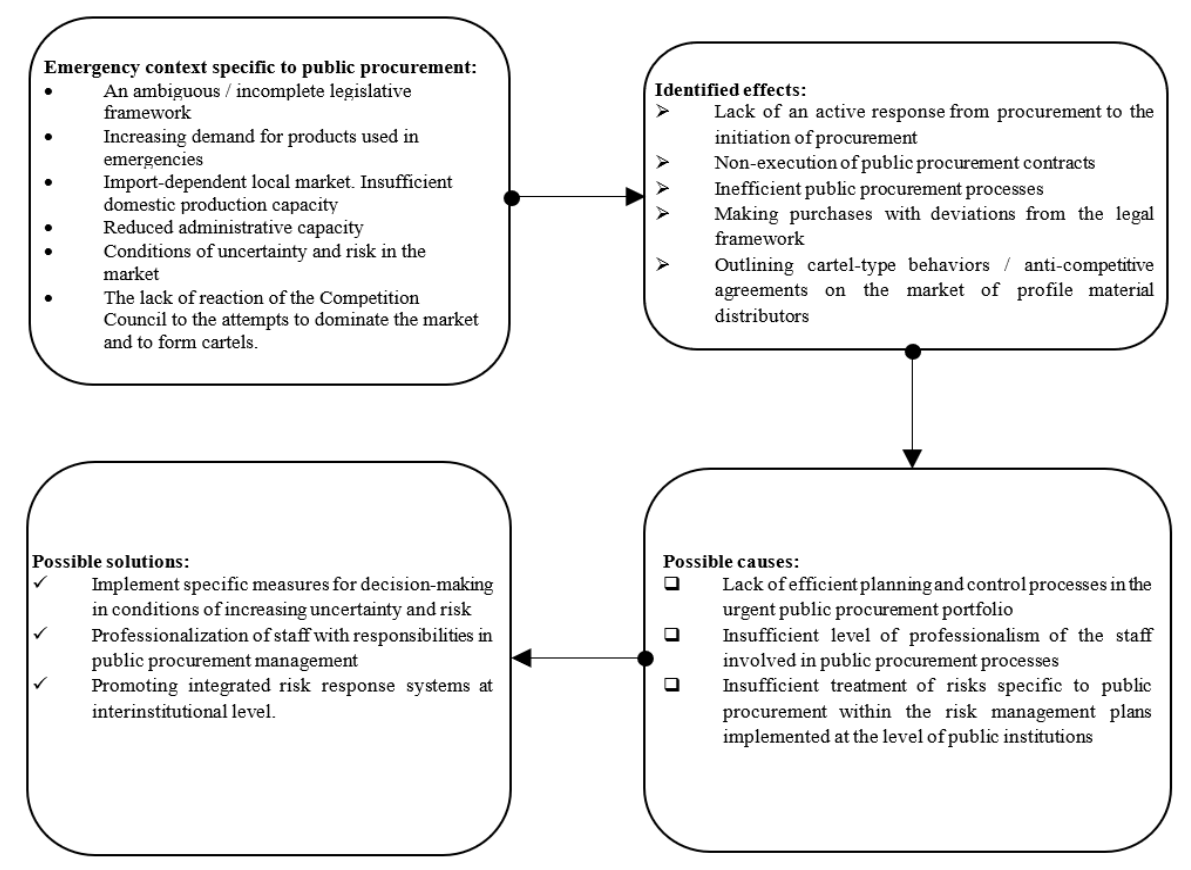

Figure 3 Causal relationships specific to public procurement processes carried out in the context of COVID-19 emergency

Source: Authors

\section{Conclusions and directions for action on decision-making in the context of emergencies.}

Starting from the idea that the mere finding of a state cannot generate a positive response of the system in the absence of the introduction of improvement measures and without proposing to fully cover this topic, we bring it forward the idea of establishing decision-making procedures and how they can compete to achieve the goals set in the portfolio of public procurement processes carried out in an emergency context.

In this new decision-making frame, by applying appropriate change management, the general objectives to be set at the level of the public procurement portfolio of products / services / works required in the context of emergencies must refer at least to:

$>$ Implementation of specific procedures for decision making in conditions of increasing uncertainty and risk;

$>$ Professionalization of staff with responsibilities in public procurement management;

$>$ Promoting integrated risk response systems, at inter-institutional level;

The achievement of these objectives must be doubled by the assumption of sets of impact and result indicators, among which we can mention, without limiting ourselves to:

$\checkmark$ R1. Increasing the response speed of contracting authorities in relation to market dynamics

$\checkmark \quad$ R2. Reducing the duration of processes associated with public procurement;

$\checkmark \quad$ R3. Establishing a set of performance indicators at the level of contracts;

$\checkmark \quad$ R4. Reducing errors and reducing the number of cases of procurement failure. 
And last but not least, it must be emphasized that any process that takes place under conditions of uncertainty and risk can be influenced by factors that are difficult to anticipate which may disrupt both the conduct of public procurement processes carried out at the level of contracting authorities and the functioning of the public procurement system as a whole.

\section{References}

“Al. I. Cuza" University Iași (n.d.), Guide to tools and good practices in public decision-making.

Adroniceanu, A. (1999), Public management, Bucharest, Economic Publishing House.

Alexandru, I. (2003), Public Administration.

Csáki, C. (2006), Investigating the decision making practice of public procurement, International public procurement conference proceedings.

Dulschi, I. (2016), The decision-making process in public administration, Public administration: theory and practice.

European Commission (2020), Communiqué 2020 / C108 I / 01. European Commission guidelines for the use of the public procurement emergency framework related to the COVID-19 crisis, Official Journal of the European Union.

European Parliament and Council of the European Union (2014), Directive 2014/24/EU, Official Journal of the European Union.

Hințea, C.E., Marius, C., Țiclău, T.C. (2015), Strategic planning and public management reform: the case of Romania, Transylvanian Review of Administrative Sciences, 30-44.

Nica, E. (2012), Public Procurement Management, Bucharest, Economic Publishing House.

Organisation for Economic Coorperation and Development (2018), Methodology for Assesing Procurement Systems (MAPS), OECD.

Popa, I.G., Ispas, R. (2019), Study regarding the planning stage of the romanian public procurement process, International Conference "Knowledge-based organization".

President of Romania (2020), Decree 195, Regarding the establishment of the state of emergency on the Romanian territory, Official Journal.

Romanian Government (1999), Emergency Ordinance 1, Regarding the state of siege and the state of emergency, Official Journal of Romania.

Romanian Government (2016), Government Decision no. 395, Methodological norms for the application of the provisions regarding the award of the public procurement contract, Official Journal of Romania.

Simon, H.A. (1979), Rational Decision Making in Business Organizations, The American Economic Review, vol. 69, 493-51.

The Romanian Parliament (2016), Public procurement law no. 98, Official Journal of Romania.

Vatamaniuc, A. (2019), Research report no.3, Iași, “Gh Asachi” University. 